\title{
Comparative ergonomic evaluation of the hand-pieces of three instrument series for root planning
}

\author{
Mario Migliario $^{1,2}$, Andrea Melle ${ }^{2}$, Paola Carcieri ${ }^{2}$, Lia Rimondini ${ }^{1,2}$ \\ ${ }^{1}$ Department of Health Sciences, “Amedeo Avogadro” University of Eastern Piedmont, Alessandria-Vercelli-Novara, Italy \\ ${ }^{2}$ Degree Course in Dental Hygiene, “Amedeo Avogadro” University of Eastern Piedmont, Alessandria-Vercelli-Novara, Italy \\ Email: mario.migliario@med.unipmn.it, mario.migliario@virgilio.it
}

Received 15 December 2013; revised 20 January 2014; accepted 28 January 2014

Copyright (C) 2014 Mario Migliario et al. This is an open access article distributed under the Creative Commons Attribution License, which permits unrestricted use, distribution, and reproduction in any medium, provided the original work is properly cited. In accordance of the Creative Commons Attribution License all Copyrights (c) 2014 are reserved for SCIRP and the owner of the intellectual property Mario Migliario et al. All Copyright (c 2014 are guarded by law and by SCIRP as a guardian.

\section{ABSTRACT}

Introduction: Musculoskeletal disorders (MSD) are the most frequent cause of disability in the working population, exceeding accidental trauma in frequency. The risk of developing work-related upper limb disorders (WURLDs) is high among dental hygienists and the most frequently affected are elderly subjects and women. Since such disorders can have a negative effect on the working life and on the quality of life, it is of vital importance to put in place preventive measures. Aim: To make a comparative analysis of the hand-pieces of three different manual instruments used for root planning. Materials and Methods: To evaluate the physical characteristics (section, diameter, external surface, weight) of the hand-pieces of three series of instruments for root planning, twentynine dental hygienists students were videoed while working clinically. They were also interviewed using a specific questionnaire to determine subjective preferences in terms of perceived efficacy, safety, comfort and general acceptability of the hand-piece used. Results: Lightness, full-cylindrical section with larger-diameter ends, and coating with anti-slip silicone are the most appreciated characteristics of a handpiece. Conclusions: Ergonomic analyses of manual instruments are not frequent in the dental field, and the literature reports no guidelines to guide selection of the type of hand-piece of manual instruments. The data gathered may help manufacturers in designing new manual instruments, and guiding professionals in their selection.

\section{KEYWORDS}

Dental Hygienist; Instrumentation; Professional

\section{Practice; Periodontal Instruments}

\section{INTRODUCTION}

Work-related musculoskeletal disorders (MSDs) are the most common occupational disorders around the world. The risk factors for developing MSDs include individual factors, physical requirements at the workplace, organizational and psychosocial factors; their prevalence varies considerably across occupations and working populations. Work-related upper limb disorders (WRULDs) are the musculoskeletal disorders of the neck and upper limbs [1]. Dental hygienists, especially those who are older and female, have a higher risk than other workers of developing upper-limb musculoskeletal disorders (WRULDs), like carpal tunnel syndrome [2-13]. Prevention of MSDs is based on eliminating or reducing risk factors, which may be subdivided into factors linked to the worker, the type of work, the working position, and the instrument used [3,5,12-19]. Correct positioning of hygienist and patient plays a fundamental role in efficient clinical treatment, and should prevent harm to the patient and limit disorders to the hygienist's musculoskeletal system [5,8,10,12-14,16-19]. Dental scaling is carried out with manual or mechanical instruments (e.g. sonic scaler system); root-planning with manual instruments, e.g. series of Gracey curettes, by pulling the working blade along the surface of dental root with a complex movement involving fingers, wrist and forearm [20]. The manual instruments used by dental hygienists for periodontal scaling and root-planning, their main occupation, comprise a hand-piece, a shank linking the hand-piece to the working tip, and a working tip or blade. The hand-piece is the part gripped during use and it may be of various shapes and sizes [10,20-22]. How and how 
firmly the hygienist holds the hand-piece when working influence the clinical procedure, but also affect his/her rate of tiring [2-6,14,15]. A correct grip gives the hygienist positive control over the instrument, providing balance and flexibility during movements, decreasing the risk of trauma to the patient's teeth and periodontal tissues, while improving the hygienist's tactile sensitivity and preventing tiring of the fingers, wrist and arms [5,14, 15,17,18,20-24]. Pinch force during dental scaling and root-planning is influenced by characteristics of handpieces of instruments: thus these characteristics are important risk factors for developing WRULDs [2-5,14,15, 22]. This study is the continuation of our previous work [25] which assessed the perceived satisfaction in using three different types of hand-piece of manual instruments (Gracey curettes) used for manual root planning. We have first evaluated the physical characteristics of the hand-pieces (section, external surface, diameter and weight) of three Gracey curette and subsequently we have recorded, through a questionnaire, the subjective impressions (perceived efficacy, safety, comfort and overall acceptability) expressed by some students of a Hygienist Dental School during work sessions in which the test instruments were used.

\section{MATERIALS AND METHODS}

\subsection{Study Design}

This comparative study was approved by the Local InterHospital Ethics Committee (EC Prot. 57/10). It evaluated three different types of hand-piece of manual instruments used for root planning (Gracey curettes) selected from among those in most widespread use in day-o-day clinical practice.

\subsection{Materials and Methods}

The hand-pieces were subdivided into three classes, con- sidering shape of section (octagonal, uniformly cylindrical, non-uniformly cylindrical), external surface (knurled, satin-finish, coated with anti-slip material), weight and diameter (Figure 1). Hand-pieces classified as A are made of steel with octagonal section, diameter $6 \mathrm{~mm}$, external surface knurled, weight $17.68 \mathrm{~g}$; type $\mathrm{B}$ are made of steel, cylindrical section, uniform diameter of 10 mm, external surface satin-finish, knurled at either end, weight 21.36 g; type $C$ have non-uniform cylindrical secon with diameter at either end of $11.5 \mathrm{~mm}$ and $8.5 \mathrm{~mm}$ in the central part, surface covered with anti-slip silicone in the central part and knurled at either end, weight $15.89 \mathrm{~g}$.

\subsection{Subjects}

Twenty-nine students of our Dental Hygiene School were enrolled in the study and, informed of the goals and study design, all gave their informed consent as per Italian Law no. 675 dated 31/12/1996 and subsequent modifications.

\subsection{Procedure}

Each student has used, for ten root-planning continually during clinical work, a series of Gracey curettes, one per type of hand-piece to be tested, distinguished with the letters $\mathrm{A} / \mathrm{B} / \mathrm{C}$.

At completion of the period of use of the instruments provided, each student filled in a questionnaire (Table 1) with questions investigating a series of parameters related to the perceived efficacy, safety and comfort during use. The replies were formulated on a 5-level ordinal scale of evaluation (from $0=$ very poor to $4=$ high); higher scores indicated a higher value of the parameter investigated.

The scores assigned to questions 2-5, 7, 9-12, 14-17, 19-24 have contributed to determine the degree of satisfaction for the section, those that refer to questions 3-6

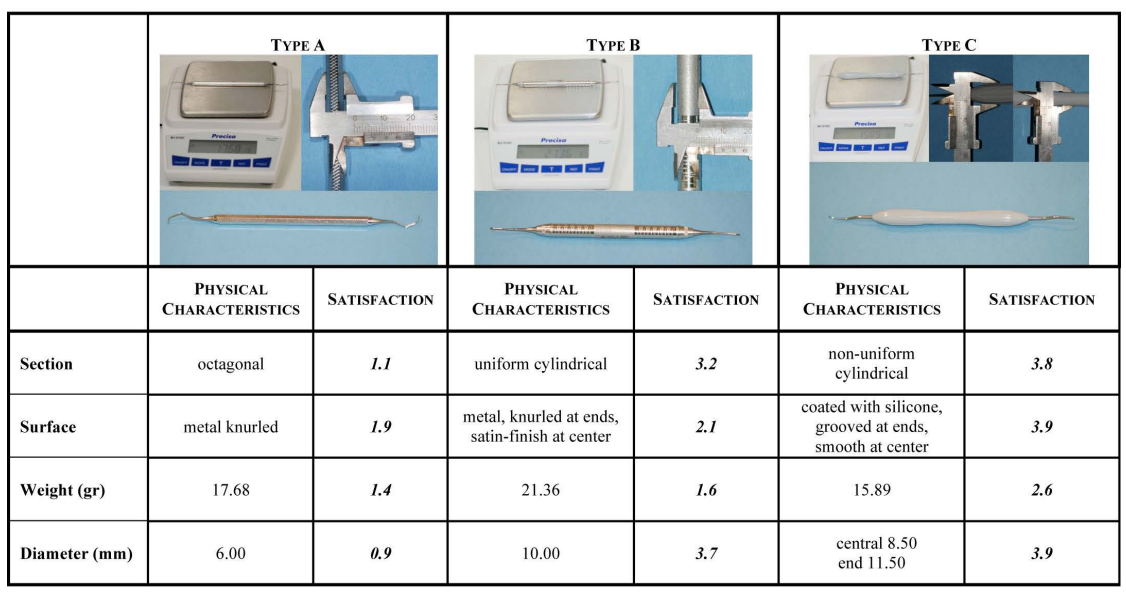

Figure 1. Physical characteristics of the three hand-pieces analyzed and satisfaction expressed (from $0=$ minimum to $4=$ maximum) by the hygienists. 
Table 1. Questionnaire: higher scores indicate a higher value of the parameter in question ( $0=$ very poor, $4=$ high).

\begin{tabular}{|c|c|c|c|c|c|c|}
\hline & Hygienist No. & \multicolumn{5}{|c|}{ Date: } \\
\hline \multicolumn{7}{|c|}{ HAND-PIECE A/B/C } \\
\hline & Evaluation of perceived efficacy & $\mathbf{0}$ & 1 & 2 & 3 & 4 \\
\hline 1 & The diameter of this hand-piece is efficacious for my work & & & & & \\
\hline 2 & The section of this hand-piece is efficacious for my work & & & & & \\
\hline 3 & This hand-piece is more efficacious than other hand-pieces & & & & & \\
\hline 4 & This hand-piece is efficacious for all types of use & & & & & \\
\hline 5 & This hand-piece is efficacious for all types of patient & & & & & \\
\hline 6 & This hand-piece is efficacious for high-precision work & & & & & \\
\hline 7 & This hand-piece is efficacious for work requiring additional force & & & & & \\
\hline \multirow[t]{2}{*}{8} & The external surface of this hand-piece is efficacious for its use & & & & & \\
\hline & Evaluation of perceived safety & $\mathbf{0}$ & 1 & 2 & 3 & 4 \\
\hline 9 & The use of this hand-piece requires particular care & & & & & \\
\hline \multirow[t]{2}{*}{10} & The grip of this hand-piece is secure & & & & & \\
\hline & Evaluation of perceived comfort during use & $\mathbf{0}$ & 1 & 2 & 3 & 4 \\
\hline 11 & This hand-piece is too thin & & & & & \\
\hline 12 & This hand-piece is too thick & & & & & \\
\hline 13 & This hand-piece is too heavy & & & & & \\
\hline 14 & This hand-piece is tiring to use & & & & & \\
\hline 15 & Use of this hand-piece requires particular strength & & & & & \\
\hline \multirow[t]{2}{*}{16} & Use of this hand-piece is appropriate for all types of site & & & & & \\
\hline & Evaluation of perceived general acceptability during use & $\mathbf{0}$ & 1 & 2 & 3 & 4 \\
\hline 17 & The shape of this hand-piece is adequate for my work & & & & & \\
\hline 18 & The color-coding facilitates recognition of the instrument & & & & & \\
\hline 19 & It is comfortable to use & & & & & \\
\hline 20 & It is simple to use & & & & & \\
\hline 21 & I would like to use this hand-piece more often & & & & & \\
\hline 22 & I would like to use this hand-piece always & & & & & \\
\hline 23 & I would avoid using this hand-piece & & & & & \\
\hline 24 & I would prefer using this hand-piece & & & & & \\
\hline
\end{tabular}

8-10, 14-24 have contributed to determine the degree of satisfaction with the surface, those that relate to questions 4, 7, 13-16, 19-24 have contributed to determine the degree of satisfaction with the weight and those relating to questions $1,3-5,7,9-11,14-17,19-24$ have contributed to determine the degree of satisfaction with the diameter.

The scores assigned to questions 1-8 have contributed to determine the degree of perceived safety, those that refer to questions 9-10 have contributed to determine the degree of safety, those that relate to questions 11-16 have contributed to determine the degree of comfort and those relating to questions 17-24 have contributed to determine the degree of overall acceptability.

The scores were then summed to obtain a value expressing the satisfaction of the physical characteristics and the perceived working on the investigated characteristic of the handle (Figure 1 satisfaction column; Table 
2).

\section{RESULTS}

The mean age of the twenty-nine dental hygiene students enrolled (11 males, 18 females) was $25 \pm 5$ years; mean height $177 \pm 15 \mathrm{~cm}$; working hand was the right in 27 cases and the left in 2 case. In regard to the physical characteristics of the hand-piece (Figure 1), type A scored 0.9 for diameter, 1.1 for section 1.4 for weight and 1.9 for surface (knurled); hand-piece type B scored 1.6 for weight, 2.1 for surface (satin-finish in the central part, knurled at either end), 3.2 for section, and 3.7 for diameter; hand-piece type $\mathrm{C}$ obtained the most positive evaluation, scoring 2.6 for weight, and 3.8 for section (non-uniform cylindrical), 3.9 for surface (coating of anti-slip silicone) and diameter (variable, ends of greater diameter than central part). In regard to perceived working satisfaction, hand-piece A scored 1.2 for safety, 1.7 for perceived efficacy and comfort, and 1.5 for overall acceptability; hand-piece B scored 2.4 for perceived efficacy and safety, and 3.2 for comfort and 2.7 for overall acceptability; hand-piece C scored 3.1 for perceived efficacy, 3.6 for safety, 3.7 for comfort and 3.5 for overall acceptability (Table 2). The comments expressed freely by the hygienists were particularly emphatic in the case of actions that require greater force, for which a cylindrical hand-piece, of greater diameter and with knurled surface, was preferred.

\section{DISCUSSION}

To remove calculus, some students preferentially used the mechanical ablator, only using manual instruments to remove localized calculus deposits in sites of difficult access and for final polishing; others used the ultrasound ablator exclusively to remove extensive and heavy deposits of calculus, preferring to use manual instruments even to remove slight deposits of calculus as well as for the finishing phase of the session. In many cases, the posture of trunk and arms while working was inappropriate, although verbally correct statements were made. This is acceptable in some ways, since students vary their posture and working method depending on their

Table 2. Perceived working satisfaction scores (from $0=$ minimum to 4 = maximum) for usability parameters expressed by the hygienists on hand-pieces analyzed.

\begin{tabular}{cccc}
\hline Parameter & Type A & Type B & Type C \\
\hline Perceived efficacy & 1.7 & 2.4 & 3.1 \\
Safety & 1.2 & 2.4 & 3.6 \\
Comfort & 1.7 & 3.2 & 3.7 \\
Overall acceptability & 1.6 & 2.7 & 3.5 \\
\hline
\end{tabular}

own and the patient's needs. Conversely, though, it should be stressed that incorrect posture and working method increase the biomechanical load acting on arms and spine, increasing the risk of developing musculoskeletal disorders over time. The instrument hand-piece was in all cases held with a modified "pencil grip", bringing the distal phalanges of the fingers into contact with the tool, including when repetitive forceful movements were made with bent wrist for prolonged times. Analysis of the students' freely-expressed comments revealed preferences for a hand-piece of greater diameter for actions requiring particular force, such as the removal of abundant accumulations of calculus, whereas in all other cases no particular preference was expressed for any particular type of hand-piece. With regard to the evaluation of the physical characteristics of the instruments (Figure 1), the best scores were achieved by the hand-pieces of nonuniform cylindrical section, surface-coated with silicone, larger diameter, and lighter weight. With regard to perceived efficacy, safety and comfort, the highest scores were awarded to hand-piece C, followed by hand-piece B. These two hand-pieces were jointly awarded the highest score for overall acceptability (Table 2). These findings are in line with those reported by Simmer-Beck and Branson [24], who recommend the use of instruments for dental hygiene having diameter $10 \mathrm{~mm}$, and with the study by Dong et al. [21,22] recommending instruments of approximately $15 \mathrm{~g}$ weight.

\section{CONCLUSION}

The literature is in agreement that hand-pieces of diameter between 6 and $8 \mathrm{~mm}$ require considerable muscular strength to control their function, such that prolonged use may lead to overloading the extrinsic and intrinsic muscles and tendons of the hand $[10,14,15,21,22,26]$ and that those of greater diameter may restrict access to the posterior regions of the patient's oral cavity [20] but they seem to be most effective in reducing fatigue [26]. It is also generally accepted that hand-pieces should preferably have knurled or grooved finish, or be coated with anti-slip material (as they require a lighter grip) and offer an adequate area of contact with the hand to avoid excessive localized pressure $[21,22,24]$. However, from a review of the literature, no indications emerge to correlate the size of the hygienist's hand with the diameter of the instruments to be used except the study of Rossi et al. [27] even if an important risk factor for developing WRULDs is forceful pinching which occurs during dental scaling and root planning [22]. Since there is no universally valid instrument ("one size fits all”) for treating different teeth in different parts of the oral cavity [24], and dental hygienists are at greater risk for developing WRULDs due long hours of repetitive work (scaling and root planning) professional ergonomics should guide the 
selection toward instruments with hand-pieces of different diameters depending on their practical use [5,14,15, $18,21,22]$; this would enable the activity of the muscles involved to be varied, reducing the risk of onset of MSDs due to repeated trauma. However, the importance of always assuming the best working position must not be forgotten (position of hygienist/position of patient/illumination) $[8,17,18,20]$. The strategies to be used to prevent MSD must include knowledge of this type of disorder, the identification of risk factors, and must also be based on the underlying principles of self-evaluation $[10,17,23]$. From our experience, educational programs in this connection are most effective when they are carried out directly at the work-place, recorded, and analyzed in periodic evaluation and correction sessions. It is also appropriate to teach moving and stretching exercises for the spine and arms, to be introduced into the daily routine $[15,17,18]$. It is to be hoped that intensive education to the prevention of MSDs be included in the initial training, then periodically repeated in post-graduation refresher courses $[5,10,16,18]$. Likewise, it is to be hoped that manufacturers of manual instruments understand the importance of a design that takes into account the individual variability among hygienists, rather than concentrating on "refined colors" and "attractive design". It is important that design be based on specific characteristics that may be adapted to the individual hygienist, thus helping to reduce risk factors connected with an inappropriate grip.

\section{ACKNOWLEDGEMENTS}

The authors thank Mrs. Frances Cooper for linguistic revision of the article.

\section{REFERENCES}

[1] Hoe, V.C.W., Urquhart, D.M., Kelsall, H.L. and Sim, M.R. (2012) Ergonomic design and training for preventing work-related musculoskeletal disorders of the upper limb and neck in adults (Review). Cochrane Database of Systematic Reviews, 15, CD008570.

[2] Conrad, J.C., Osborn, J.B., Conrad, K.J. and Jetzer, T.C. (1990) Peripheral nerve dysfunction in practicing dental hygienists. Journal of Dental Hygiene, 64, 382-387.

[3] Rice, V.J., Nindl, B. and Pentikis, J.S. (1996) Dental workers, musculoskeletal cumulative trauma, and carpal tunnel syndrome: Who is at risk? A pilot study. International Journal of Occupational Safety and Ergonomics, 2, 218-233.

[4] Michalak-Turcotte, C. (2000) Controlling dental hygiene work-related musculoskeletal disorders: The ergonomic process. Journal of Dental Hygiene, 74, 41-48.

[5] Lalumandier, J.A. and McPhee, S.D. (2001) Prevalence and risk factors of hand problems and carpal tunnel syndrome among dental hygienists. Journal of Dental Hy- giene, 75, 130-134.

[6] Anton, D., Rosecrance, J., Merlino, L. and Cook, T. (2002) Prevalence of musculoskeletal symptoms and carpal tunnel syndrome among dental hygienists. American Journal of Industrial Medicine, 42, 248-257. http://dx.doi.org/10.1002/ajim.10110

[7] Werner, R.A., Hamann, C., Franzblau, A. and Rodgers, P.A. (2002) Prevalence of carpal tunnel syndrome and upper extremity tendinitis among dental hygienists. Journal of Dental Hygiene, 76, 126-132.

[8] Valachi, B. and Valachi, K. (2003) Mechanisms leading to musculoskeletal disorders in dentistry. Journal of the American Dental Association, 134, 1344-1350. http://dx.doi.org/10.14219/jada.archive.2003.0048

[9] Treaster, D.E. and Burr, D. (2004) Gender differences in prevalence of upper extremity musculoskeletal disorders. Ergonomics, 47, 495-526. http://dx.doi.org/10.1080/00140130310001638171

[10] Sartorio, F., Vercelli, S., Ferriero, G., D’Angelo, F., Migliario, M. and Franchignoni, M. (2005) Work-related musculoskeletal diseases in dental professionals. 1. Prevalence and risk factors. Giornale Italiano di Medicina del Lavoro ed Ergonomia, 27, 165-169.

[11] Hayes, M., Cockrell, D. and Smith, D.R. (2009) A systematic review of musculoskeletal disorders among dental professionals. International Journal of Dental Hygiene, 7, 159-165. http://dx.doi.org/10.1111/j.1601-5037.2009.00395.x

[12] Hayes, M.J., Smith, D.R. and Cockrell, D. (2010) An international review of musculoskeletal disorders in the dental hygiene profession. International Dental Journal, 60, 343-352.

[13] Morse, T., Bruneau, H. and Dussetschleger, J. (2010) Musculoskeletal disorders of the neck and shoulder in the dental professions. Work, 35, 419-429.

[14] Gerwatowski, L.J., McFall, D.B. and Stach, D.J. (1992) Carpal tunnel syndrome. Risk factors and preventive strategies for the dental hygienist. Journal of Dental Hygiene, 66, 89-94.

[15] Liskiewicz, S.T. and Kerschbaum, W.E. (1997) Cumulative trauma disorders: An ergonomic approach for prevention. Journal of Dental Hygiene, 71, 162-167.

[16] Sanders, M.A. and Turcotte, M.C. (2002) Strategies to reduce work-related musculoskeletal disorders in dental hygienists: Two case studies. Journal of Hand Therapy, 15, 363-374. http://dx.doi.org/10.1016/S0894-1130(02)80008-4

[17] Valachi, B. and Valachi, K. (2003) Preventing musculoskeletal disorders in clinical dentistry: Strategies to address the mechanisms leading to musculoskeletal disorders. Journal of the American Dental Association, 134, 1604-1612. http://dx.doi.org/10.14219/jada.archive.2003.0106

[18] Sartorio, F., Franchignoni, F., Ferriero, G., Vercelli, S., Odescalchi, L., Augusti, D. and Migliario, M. (2005) Work-related musculoskeletal disorders in dental professionals. 2. Prevention, ergonomic strategies and therapeutic programs. Giornale Italiano di Medicina del Lavoro 
ed Ergonomia, 27, 442-448.

[19] Gupta, S. (2011) Ergonomic applications to dental practice. Indian Journal of Dental Research, 22, 816-822. http://dx.doi.org/10.4103/0970-9290.94677

[20] Matsuda, S.A. (1999) Instruments and principles for instrumentation. In Wilkins, E.M., Ed., Clinical Practice of Dental Hygienist, 10th Edition, Lippincott Williams \& Wilkins Inc., Baltimore.

[21] Dong, H., Barr, A., Loomer, P., Laroche, C., Young, E. and Rempel, D. (2006) The effects of periodontal instrument handle design on hand muscle load and pinch force. Journal of the American Dental Association, 137, 11231130. http://dx.doi.org/10.14219/jada.archive.2006.0352

[22] Dong, H., Loomer, P., Barr, A., Laroche, C., Young, E. and Rempel, D. (2007) The effect of tool handle shape on hand muscle load and pinch force in a simulated dental scaling task. Applied Ergonomics, 38, 525-531. http://dx.doi.org/10.1016/j.apergo.2006.09.002

[23] Meador, H.L. (1993) The Biocentric technique: A guide to avoiding occupational pain. Journal of Dental Hygiene,
67, 38-51.

[24] Simmer-Beck, M. and Branson, B.G. (2010) An evidence-based review of ergonomic features of dental hygiene instruments. Work, 35, 477-485.

[25] Migliario, M., Franchignoni, M., Soldati, L., Melle, A., Carcieri, P. and Ferriero, G. (2012) Ergonomic analysis of the handle of manual instruments for dental hygiene. Giornale Italiano di Medicina del Lavoro ed Ergonomia, 34, 202-206.

[26] Rempel, D., Lee, D.L., Dawson, K. and Loomer, P. (2012) The effects of periodontal curette handle weight and diameter on arm pain: A four-month randomized controlled trial. Journal of the American Dental Association, 143, 1105-1113. http://dx.doi.org/10.14219/jada.archive.2012.0041

[27] Rossi, J., Berton, E., Grélot, L. and Barla, C. (2012) Characterisation of forces exerted by the entire hand during the power grip: Effect of the handle diameter. Ergonomics, 55, 682-692.

http://dx.doi.org/10.1080/00140139.2011.652195 